\title{
UPAYA KONSERVASI TANAMAN AKUMULATOR UNTUK MEMINIMAL CEMARAN LOGAM BERAT DI LAHAN TAMBANG TIMAH, PULAU BANGKA
}

\author{
Diah Mustikasari \\ Program Studi Biologi Universitas Wanita Internasional Bandung \\ E-mail: diah.mustikasari83@gmail.com
}

\begin{abstract}
Tin mining activities in Bangka Island have caused ecosystem damages including deforestation which has an impact on the loss of local flora and fauna, ecological imbalances, decreases in land and water quality, and heavy metal contamination such as $\mathrm{Pb}, \mathrm{Sn}, \mathrm{Zn}, \mathrm{Mn}, \mathrm{Fe}, \mathrm{Cr}, \mathrm{Cu}$, $\mathrm{Ni}, \mathrm{Cd}$, and As. The post-mining ecosystem must be restored to restore its function as a life supporting system for the organisms in the ecosystem. This paper aimed to elaborate information related to the condition of postmining land related to ecological damage and heavy metal contamination and the potential for the conservation efforts of bioaccumulator plants which can reduce heavy metal contamination and improve the quality of land functions. This paper was expected to be one of the references for making decisions on sustainable post-mining environmental management so that the land is habitable for the flora and fauna of the ecosystem. Some plants which have heavy metal accumulation potential are Calophyllum pulcherrimum, Cratoxylum formosum, Gluta velutina Blume, Gordonia excelsa Blume, Ilex cymosa Blume, Ixonanthes petiolaris Blume, Lithocarpus sp, Lophopetalum javanicum, Schima wallichii, Tristaniopsis whiteana, Acacia mangium, Enterolobium cyclocarpum, Gliricidia sepium, Delonix regia, dan Cassia siamea Lamk. The accumulator plants develop their mechanism such as rhizodegradation, phytostabilization, phytodegradation, phytoaccumulation/ phytoextraction, phytovolatilization, phytofiltration, dan phytodesalination.
\end{abstract}

Keywords: Tin mining, Ecosystem degradation,Cconservation, Bioaccumulator plants, Heavy metals

\section{PENDAHULUAN}

$\mathrm{I}$ ndonesia memiliki sumber daya alam berupa bahan tambang yang melimpah, salah satunya adalah timah. Pulau Bangka merupakan bagian dari Provinsi Kepulauan Bangka Belitung sebagai penghasil timah terbesar di Indonesia. Kekayaan alam ini telah ditambang sejak tahun 1668 dan produksi timah Indonesia telah menempatkannya sebagai produsen timah terbesar kedua di dunia setelah China (Irawan et al., 2014; Syarbaini et al., 2014).

Aktivitas pertambangan timah yang dilakukan di daratan maupun perairan menyebabkan terjadinya permasalahan lingkungan seperti perubahan ekosistem, kerusakan pengairan alami, destruksi terhadap habitat alami, dan cemaran (Ashraf et al., 
2010). Pada umumnya, kerusakan ekosistem terbesar yang terjadi di lahan pertambangan timah adalah deforestasi hutan yang berdampak pada hilangnya flora dan fauna penghuni ekosistem tersebut serta cemaran logam berat yang ditimbulkan pascaaktivitas pertambangan timah seperti $\mathrm{Pb}, \mathrm{Sn}, \mathrm{Zn}, \mathrm{Mn}, \mathrm{Fe}, \mathrm{Cr}, \mathrm{Cu}, \mathrm{Ni}, \mathrm{Cd}$, dan As (Henny, 2011; Ashraf et al., 2012a; Rosidah dan Henny, 2012; Daniel et al., 2014). Secara tidak langsung, kerusakan dan ketidakseimbangan di ekosistem tersebut akan berdampak pada kehidupan di makro- dan mikroekosistem (Fan et al., 2002; Vyas dan Pancholi, 2009; Ashraf et al., 2010; Singh et al., 2013; Giri et al., 2014; Lad dan Samant, 2015).

Upaya untuk mengembalikan fungsi ekosistem pascatambang timah sangat dibutuhkan. Upaya konservasi melalui pengelolaan organisme setempat, khususnya tanaman diperlukan untuk mendukung eksistensi ekosistem yang layak bagi organisme. Tanaman yang dikonservasi adalah jenis tanaman yang banyak ditemukan di lahan pertambangan. Hal ini diharapkan agar tanaman tersebut mampu menjalankan berbagai fungsinya secara maksimal, salah satunya forestasi dan dekontaminasi atau akumulasi terhadap logam berat yang ditimbulkan pascatambang timah.

\section{EKOSISTEM PASCATAMBANG TIMAH}

Kegiatan pertambangan timah yang dilakukan telah menyebabkan terjadinya perubahan pada ekosistem tersebut. Aktivitas pertambangan timah menghasilkan berbagai limbah seperti tailing, minyak, dan bahan bakar dari peralatan pertambangan (Ahmad, 2013).

Karakteristik di lokasi pertambangan timah berupa kondisi $\mathrm{pH}$ yang relatif asam hingga netral (4,8-7,2) (Ashraf et al., 2013). Kondisi lainnya adalah terjadinya defisiensi nutrisi dan nilai oksigen terlarut yang rendah (Kurniawan, 2016). Di ekosistem tanah, aktivitas pertambangan timah menyebabkan rendahnya kapasitas pertukaran ion (cation exchange capacity) yaitu sekitar 0,4-3,9. Selain itu, bahan organik, total nitrogen, ketersediaan fosfor, makro nutrien, dan kandungan tanah lempung juga rendah serta kandungan pasir yang tinggi hingga lebih dari $80 \%$ (Nurtjahya et al., 2009; Oktavia et al., 2014). Limbah pertambangan timah yang dihasilkan juga menyebabkan terjadinya kerusakan ekosistem dan cemaran logam berat (Ashraf et al., 2011a; Ashraf et al., 2011b; Ashraf et al., 2012a; Ashraf et al., 2012b). Pada Gambar 1 ditampilkan beberapa kondisi ekosistem pascatambang timah di Pulau Bangka.

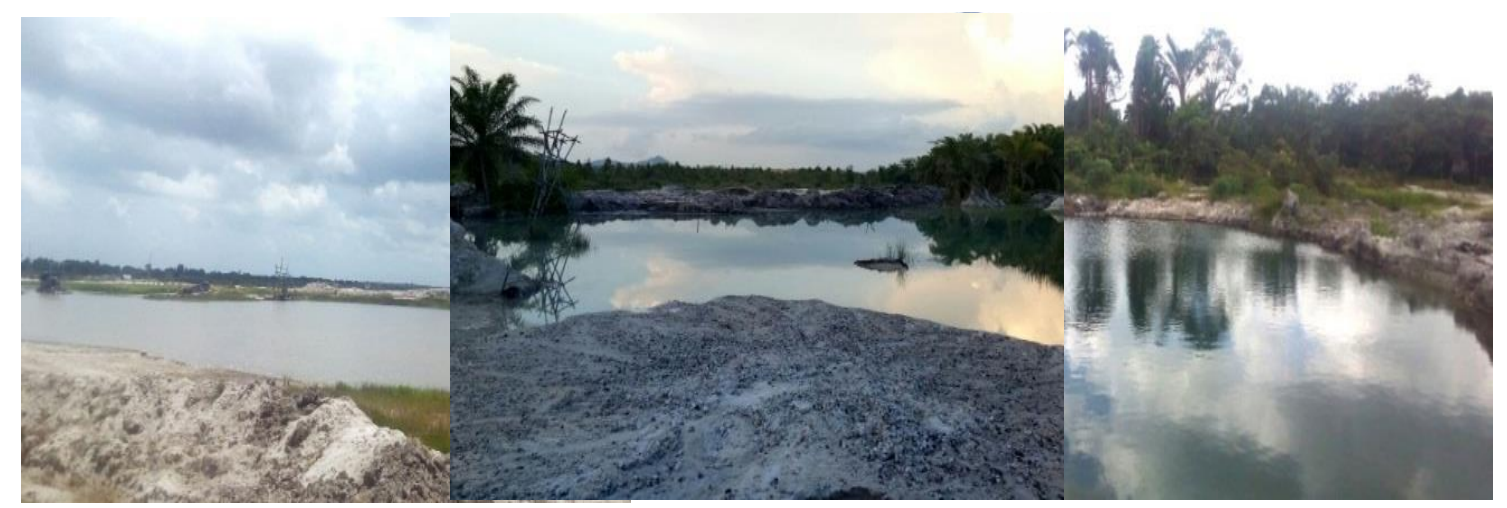

Gambar 1. Kondisi ekosistem Pascatambang Timah di Pulau Bangka 


\section{KONSERASI DAN FITOREMEDIASI}

\section{Konservasi}

Konservasi adalah suatu upaya untuk melestasikan dan melindungi biodiversitas (Hayes dan Ostrom, 2005). Upaya konservasi tidak dapat dilakukan secara parsial dengan tujuan hanya untuk melestarikan atau melindungi suatu organisme tertentu. Akan tetapi, konservasi harus dilakukan dengan suatu perencanaan yang komprehensif. Hal ini dikarenakan pelestarian suatu organisme tidak dapat dilepaskan dari hubungannya dengan faktor-faktor lingkungan lainnya. Relasi dan konektivitas dengan variabel fisik, kimia, maupun biologi diperlukan untuk menjadikan upaya konservasi tersebut mencapai sasaran yang diharapkan secara berkesinambungan (Margules dan Pressey, 2000).

\section{Fitoremediasi}

Fitoremediasi adalah bagian dari istilah bioremediasi, yaitu suatu teknologi yang memanfaatkan organisme hidup untuk menurunkan konsentrasi cemaran dari suatu lingkungan (Samal dan Kotiyal, 2013). Bioremediasi telah digunakan secara luas dan dipercaya sebagai salah satu teknologi penghilangan cemaran atau polutan yang lebih aman, lebih bersih, efektif, dan ramah lingkungan (Kensa, 2011; Bhatnagar dan Kumari, 2013; Kulshreshtha et al., 2014).

Keuntungan lain dari bioremediasi adalah biaya yang lebih murah dibandingkan dengan teknik konvensional, dapat dilakukan di lokasi yang tercemar untuk mengurangi risiko paparan terhadap orang yang melakukan pembersihan, penghilangan limbah terjadi secara permanen, dapat dipadukan dengan teknis fisik dan kimiawi, teknologi noninvasif, serta lingkungan tidak terganggu selama proses remediasinya (Vidali, 2001).

Apabila dihubungkan dengan cemaran logam berat, sejumlah tanaman telah dikaji memiliki kemampuan untuk mengakumulasi logam berat dan mampu bertahan hidup pada kondisi cemaran dan lingkungan ekstrem seperti padi (Kien et al., 2015), kentang, brokoli, dan lada (Antonious dan Snyder, 2007). Namun, pemilihan tanaman untuk remediasi haruslah memperhatikan banyak aspek, salah satunya adalah rantai akumulasi yang terjadi pada tanaman tidak berpindah ke tingkat konsumen lebih tinggi yang mengkonsumsinya. Oleh karenanya, pemilihan tanaman fitoremediator perlu mencermati beberapa hal seperti faktor translokasi cemaran, rasio konsentrasi logam dengan akar tanaman yang mengindikasikan mekanisme toleransi internal di dalam detoksifikasi logam, dan memiliki kemampuan fitoekstraksi (Nouri et al., 2009).

Apabila dihubungkan dengan cemaran logam, termasuk logam berat yang ditemukan di lokasi pasca tambang timah seperti $\mathrm{Fe}, \mathrm{Al}, \mathrm{Cu}, \mathrm{Zn}, \mathrm{Pb}, \mathrm{Cd}, \mathrm{Ni}, \mathrm{Mn}, \mathrm{Cr}$, dan As (Henny, 2011; Rosidah dan Henny, 2012; Ashraf et al., 2012a; Daniel et al., 2014), maka diperlukan tanaman yang mampu mereduksi cemaran logam berat tersebut dan mampu hidup pada lingkungan pertambangan timah. Selain itu, tanaman fitoremediator tersebut dapat berasal dari kelompok tumbuhan tingkat tinggi yang bukan merupakan tanaman konsumsi untuk mendukung penyerapan logam berat dan menjamin tidak terjadinya transfer akumulasi yang terjadi di tanaman ke manusia.

\section{Tanaman Akumulator Logam Berat}

Sejumlah tanaman telah dikaji memiliki kemampuan akumulator terhadap logam berat. Hasil analisis menunjukkan bahwa tanaman teki ladang (Cyperus rotundus L) 
memiliki potensi sebagai tin-hyperaccumulator plant. Tanaman pakuan Lycopodium cernuum, alang-alang (Imperata cylindrical), putri malu (Mimosa pudica Linn), keramunting (Melastoma malabathricum), lotus atau seroja (Nelumbo nucifera), rumput perumpung (Phragmites australis L.), pakuan (Pteris vittata L.), dan kiambang (Salvinia molesta) merupakan metal accumulator. Tanaman akasia (Acacia podalyriaefolia G.Don), anggrek (Bulb Vanisium), simpur (Dillenia reticulate King), belimbing londo (Eugenia reinwardtiana), resam (Gleichenia linearis), ubi kayu (Manihot esculenta Crantz), rumput paitan (Paspalum conjugatum Berguis), konyal (Passiflora suberosa), tebu (Saccharum officinarum), dan anggur (Vitis trifolia Linn.) merupakan tanaman yang toleran terhadap logam berat (Ashraf et al., 2011a).

Tanaman-tanaman tersebut memiliki potensi sebagai akumulator. Akan tetapi, beberapa jenis tanaman tersebut masih berpotensi memindahkan konsentasi logam ke konsumen pada tingkat trofik yang lebih tinggi. Hal ini dikarenakan tanaman seperti rumput, tebu, atau anggur sangat memungkinkan mentranslokasikan logam menuju ke konsumen yang mengkonsumsinya. Oleh karenanya, tanaman tingkat tinggi yang bukan merupakan tanaman konsumsi menjadi solusi sebagai tanaman akumulator yang memiliki risiko translokasi logam rendah. Tanaman tingkat tinggi tersebut akan mengakumulasi logam di akar dan batang dan kemudian dimanfaatkan untuk furniture dan bukan untuk dikonsumsi.

Beberapa jenis tanaman berpohon yang banyak dijumpai di lahan pertambangan timah di Pulau Bangka antara lain bintangur (Calophyllum pulcherrimum), pohon idat (Cratoxylum formosum), rengas (Gluta velutina Blume), pohon Gordonia excelsa Blume, kambasira (Ilex cymosa Blume), pohon Ixonanthes petiolaris Blume, kayu pasang (Lithocarpus sp), perupuk (Lophopetalum javanicum), medang gatal (Schima wallichii), dan belawan putih (Tristaniopsis whiteana) (Nurtjahya et al., 2009).

Tanaman lainnya yang juga ditemukan di lahan pertambangan timah adalah akasia (Acacia mangium), sengon (Enterolobium cyclocarpum), gamal (Gliricidia sepium), flamboyan (Delonix regia), dan johar (Cassia siamea Lamk.) (Narendra dan Pratiwi, 2016; Jeyanny et al., 2017). Kesemua tanaman tersebut mampu bertahan hidup pada kondisi ekstrem pascatambang timah dan memiliki kemampuan akumulasi terhadap logam berat yang ada di lingkungan tersebut.

Tanaman-tanaman tingkat tinggi yang bersifat akumulator terhadap logam dan banyak ditemukan di lokasi pertambangan timah tersebut harus dilindungi eksistensinya. Hal ini bertujuan untuk menjaga kehidupan di ekosistem pascatambang timah tersebut agar tetap lestari dan meminimalkan cemaran logam berat yang terdapat di lingkungan maupun akumulasinya pada konsumen selanjutnya.

\section{Mekanisme Traslokasi Logam Berat}

Tanaman tingkat tinggi dipilih sebagai fitoremediator di ekosistem pertambangan timah karena kemampuan mengakumulasi logam lebih stabil dibandingkan organisme lainnya. Tanaman non konsumsi dipilih agar perpindahan logam dari lingkungan tidak mengikuti rantai makanan yang berdampak negatif bagi kesehatan konsumen, khususnya manusia. Perpindahan atau dekontaminasi logam berat dari lingkungan melalui tanaman terjadi dengan beberapa mekanisme, yaitu rhizodegradation, phytostabilization, phytodegradation, phytoaccumulation/ phytoextraction, dan phytovolatilization (Singh et al., 2011) (Gambar 2).

Beberapa definisi dari mekanisme tersebut adalah rhizodegradation yang merujuk pada memutusan ikatan polutan organik oleh mikroorganisme yang berada di perakaran 
(rhizosphere). Mekanisme phytostabilization/phytoimmobilization ini menggunakan tanaman tertentu untuk menstabilkan kontaminan pada lahan tercemar. Teknik ini digunakan untuk mereduksi mobilitas dan bioavailabilitas polutan di lingkungan dan kemudian mencegah perpindahannya ke air tanah atau rantai makanan. Phytodegradation adalah degradasi cemaran organik oleh tanaman dengan bantuan enzim seperti dehalogenase dan oxygenase serta tidak tergantung pada mikroorganisme rhizozperik. Phytoextraction yang juga dikenal dengan istilah phytoaccumulation, phytoabsorption, atau phytosequestration adalah pemindahan kontaminan dari tanah atau air melalui akar tanaman dan memindahkan (trakslokasi) serta mengakumulasinya. Phytovolatilization adalah pemindahan polutan dari tanah melalui tanaman dan mengkonversinya menjadi bentuk volatil atau mudah menguap dan kemudian

melepaskannya ke atmosfer. Selain beberapa mekanisme tersebut, proses lainnya yang dapat dilakukan oleh tanaman fitoremediator adalah phytofiltration yang berperan menghilangkan polutan dari permukaan air atau limbah perairan melalui proses filtrasi serta phytodesalination yang merujuk pada penggunaan tanaman halofiitik untuk menghilangkan garam dari tanah terkontaminasi garam (Ali et al., 2013).

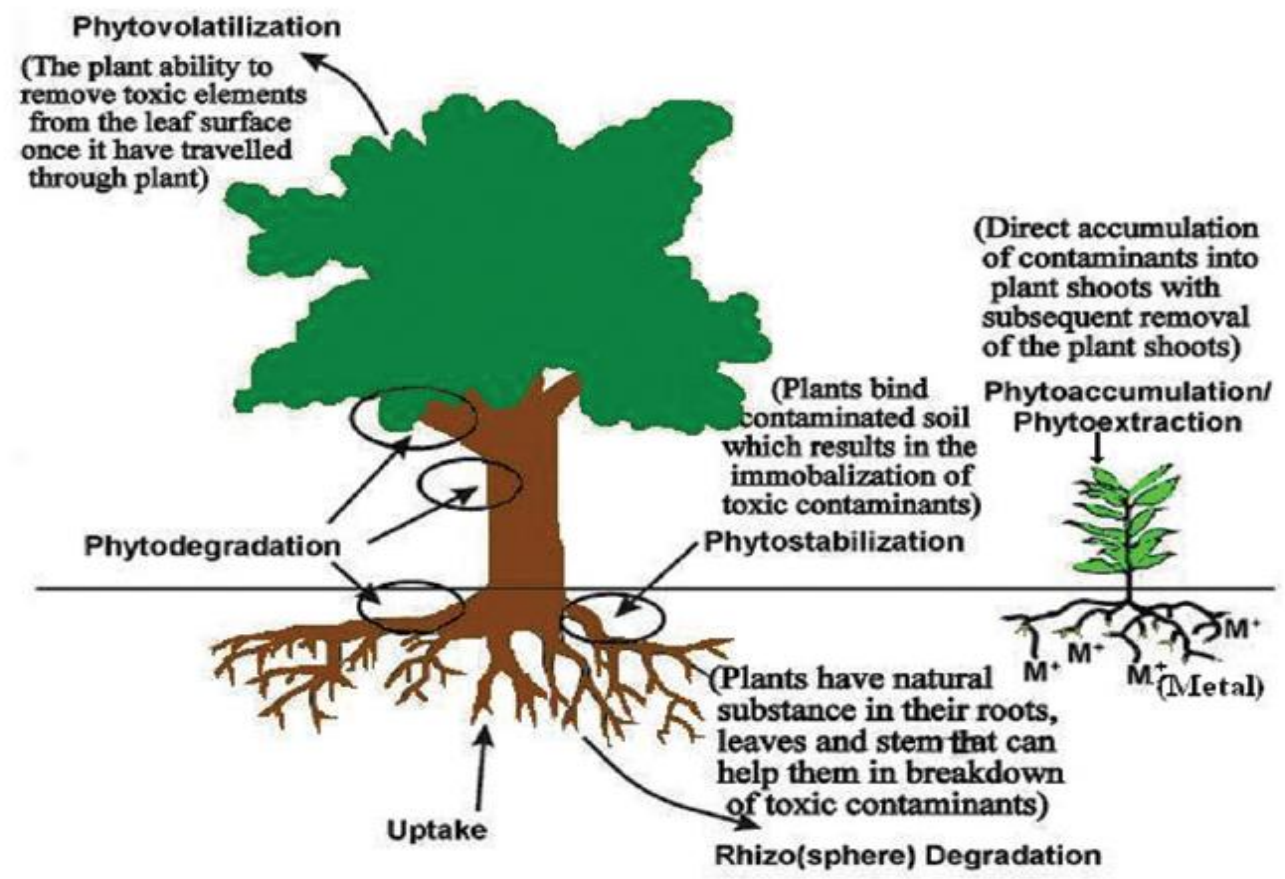

Gambar 2. Mekanisme Translokasi dan Dekontaminasi Polutan oleh Tanaman

\section{KESIMPULAN}

Pascapertambangan timah di Pulau Bangka menyisakan berbagai permasalahan lingkungan diantaranya deforestasi dan cemaran logam berat. Upaya penyelamatan lingkungan diperlukan untuk mengembalikan fungsi lahan. Upaya konservasi diharapkan dapat menjadi solusi permasalahan tersebut, yaitu menjaga eksistensi tanaman setempat di lokasi pertambangan timah. Sejumlah tanaman akumulator berpotensi untuk dikonservasi dalam rangka menjaga eksistensi ekosistem pascatambang timah. Beberapa jenis tanaman akumulator yang memiliki peran pengendalian cemaran logam berat antara lain Calophyllum pulcherrimum, Cratoxylum 
formosum, Gluta velutina Blume, Gordonia excelsa Blume, Ilex cymosa Blume, Ixonanthes petiolaris Blume, Lithocarpus sp, Lophopetalum javanicum, Schima wallichii, Tristaniopsis whiteana, Acacia mangium, Enterolobium cyclocarpum, Gliricidia sepium, Delonix regia, dan Cassia siamea Lamk. Kemampuan dari tanaman akumulator tersebut diharapkan mampu menjalankan fungsinya untuk meremediasi lingkungan pascatambang timah.

\section{DAFTAR PUSTAKA}

Ahmad, F. (2013). Distribusi dan prediksi tingkat pencemaran logam berat ( $\mathrm{Pb}, \mathrm{Cd}, \mathrm{Cu}, \mathrm{Zn}$, dan Ni) dalam sedimen di perairan Pulau Bangka menggunakan indeks beban pencemaran dan indeks geoakumulasi. Jurnal Ilmu dan Teknologi Kelautan Tropis, 5(1), 170-181.

Ali, H., Khan, E., \& Sajad M.A. (2013). Review: phytoremediation of heavy metals-concepts and applications. Chemosphere, 2013(91), 869-881.

Antonius, G.F., \& Snyder, J.C. (2007). Accumulation of heavy metals in plants and potential phytoremediation of lead by potato, Solanum tuberosum L. Journal of Environmental Science and Health, Part A: Toxic/Hazardous Substances and Environmental Engineering, 42(6): 811-816.

Ashraf, M.A., Maah, M.J., \& Yusoff, I. (2010). Study of water quality and heavy metals in soil \& water of ex-mining area Bestari Jaya, Peninsular Malaysia. International Journal of Basic \& Applied Sciences IJBAS-IJENS, 10(3): 7-12.

Ashraf, M.A., Maah, M.J., \& Yusoff, I. (2011a). Heavy metals accumulation in plants growing in ex tin mining catchment. International Journal of Environmental Science and Technology 8(2): 401-416.

Ashraf, M.A., Maah, M.J., \& Yusoff, I. (2011b). Analysis of physio-chemical parameters and distribution of heavy metals in soil and water of ex-mining area of Bestari Jaya, Peninsular Malaysia. Asian Journal of Chemistry, 23(8): 3493-3499.

Ashraf, M.A., Maah, M.J., \& Yusoff, I. (2012a). Speciation of heavy metals in the sediments of former tin mining catchment. Iranian Journal of Science \& Technology, 2012(A2): 163-180.

Ashraf, M.A., Maah, M.J., \& Yusoff, I. (2012b). Morphology, geology and water quality assessment of former tin mining catchment. The Scientific World Journal, 2012: 1-15.

Ashraf, M.A., Maah, M.J., \& Yusoff, I. (2013). Evaluation of natural phytoremediation process occurring at ex-tin mining catchment. Chiang Mai Journal of Science, 40(2): 198-213.

Bhatnagar, S. \& Kumari, R. (2013). Bioremediation: a sustainable tool for environmental management-a review. Annual Review \& Research in Biology, 3(4): 974-993.

Daniel, V.N., Chudusu, E.S., Chup, J.A., \& Pius, N.D. (2014). Variations of heavy metals in agricultural soils irrigated with tin water in Heipang District of Barkin Ladi, Plateau State, Nigeria. International Journal of Science and Technology, 3(5), 255-263.

Fan, Y., Lu, Z., Chen, J., Zhou, Z., \& Wu, G. (2003). Major ecological and environmental problems and the ecological reconstruction technologies of the coal mining areas in China. Acta Ecologica Sinica, 23(10), 2144-2152.

Giri, K., Mishra, G., Pandey, S., Verma, P. K., Kumar, R., \& Bisht, N. S. (2014). Ecological degradation in northeastern coal fields: Margherita Assam. International Journal of Science, Environment and Technology, 3(3), 881-884.

Hayes, T., \& Ostrom, E. (2005). Conserving the world's forest: are protected areas the only why?. Indiana Law Review's Symposium on The Law and Economics of Development and Environment at the Indiana University School of Law-Indianapolis, on January 22, 2005

Henny, C. (2011). Bioakumulasi beberapa logam pada ikan di kolong bekas tambang timah di Pulau Bangka. Limnotek, 18(1), 83-95. 
Irawan, R.R., Sumarwan, U., Suhardjo, B., \& Djohar, S. (2014). Strategic model of tin mining industry in indonesia (Case study of Bangka Belitung Province). International Journal of Business and Management Review, 2(3), 48-58.

Jeyanny, V., Zuhaidi, Y.A., Fakhri, M.I., \& Syaliny, G. (2017). Phytoremediation of heavy metals using Acacia mangium in Rahman Hydraulic Tin (RHT) tailings. Pp 38-43 in Ho WM, Jeyanny V, Sik HS \& Lee CT (eds) Proceedings of the Seminar on Reclamation, Rehabilitation and Restoration of Disturbed Sites: Planting of National and IUCN Red List Species. FRIM Proceedings No. 14. 1517 August 2017, Kuala Lumpur. ISBN 978-967-2149-08-8

Kensa, V.M. (2011). Bioremediation-an overview. Journal of Industrial Pollution Control, 27(2), 161168.

Kien, C. N., Noi, N. V., Son, L. T., Ngoc, H. M., Tanaka, S., Nishina, T., \& Iwasaki, K. (2010). Heavy metal contamination of agricultural soils around a chromite mine in Vietnam. Soil Science \& Plant Nutrition, 56(2), 344-356.

Kulshreshtha, A., Agrawal, R., Barar, M., \& Saxena, S. (2014). A review on bioremediation of heavy metals in contaminated water. IOSR Journal of Environmental Science, Toxicology and Food Technology, 8(7), 44-50.

Kurniawan, A. (2016). Microorganism communities response of ecological changes in post tin mining ponds. Journal of Microbiology and Virology, 6(1): 17-26.

Lad, R.J., \& Samant, J.S. (2015). Impact of bauxite mining on soil: a case study of bauxite mines at Udgiri, Dist-Kolhapur, Maharashtra State, India. International Research Journal of Environment Sciences, 4(2), 77-83.

Margules, C.R., \& Pressey, R.L. (2000). Systematic conservation planning. Nature, 405(6783), 243-253.

Narendra, B.H., \& Pratiwi, P. (2016). Adaptability of some legume trees on quartz tailings of a former tin mining area in Bangka Island, Indonesia. Journal of Degraded and Mining Lands Management, $4(1), 671$.

Nouri, J., Khorasani, N., Lorestani, B., Karami, M., Hassani, A.H., \& Yousefi, N. (2009). Accumulation of heavy metals in soil and uptake by plant species with phytoremediation potential. Environmental Earth Sciences, 59(2), 315-323.

Nurtjahya, E., Setiadi, D., Guhardja, E., \& Setiadi, Y. (2009). Succession on tin-mined land in Bangka Island. Blumea-Biodiversity, Evolution and Biogeography of Plants, 54(1-2), 131-138.

Oktavia, D., Setiadi, Y., \& Hilwan, I. (2014). Sifat fisika dan kimia tanah di hutan kerangas dan lahan pasca tambang timah Kabupaten Belitung Timur. Jurnal Silvikultur Tropika, 5(3), 149-154.

Rosidah \& Henny, C. (2012). Kajian logam Fe, Al, Cu dan Zn pada perairan kolong paska penambangan timah di Pulau Bangka. Prosiding Seminar Nasional Limnologi VI Tahun 2012.

Samal, B., \& Kotiyal, P.B. (2013). Bioremediation of copper contaminated soil using bacteria. Octa Journal of Environmental Research, 1(1), 05-08.

Singh, E., Sharma, S., Pareek, A., Dwivedi, J., Yadav, S., \& Sharma, S. (2011). Phytochemistry, traditional uses and cancer chemopreventive activity of Amla (Phyllanthus emblica): The Sustainer. Journal of Applied Pharmaceutical Science, 2(1), 176-183.

Singh, P.K., Imam, A., Singh, R., Singh, D., \& Sharma, S. (2013). A study about ecological imbalance in Surguja (India) coalfield area due to mining. International Research Journal of Environment Sciences, 2(4), 10-14.

Syarbaini, S., Warsona, A., \& Iskandar, D. (2014). Natural Radioactivity in Some Food Crops from Bangka-Belitung Islands, Indonesia. Atom Indonesia, 40(1), 27-32.

Vidali, M. (2001). Bioremediation. an overview. Pure and Applied Chemistry, 73(7), 1163-1172.

Vyas, A., \& Pancholi, A. (2009). Environmental degradation due to mining in South Rajasthan: a case study of Nimbahera, Chittorgarh (India). Journal of Environmental Research and Development, $4(2), 405-412$. 